\title{
Commentary: When is less more?
}

\author{
Pranava Sinha, MD
}

Luo and colleagues ${ }^{1}$ present an interesting technique as an alternative to the Doty technique ${ }^{2}$ for repair of supravalvular aortic stenosis. The authors present 8 patients with a median age and weight of 12.4 years and $7.6 \mathrm{~kg}$, respectively, who underwent supravalvular aortic stenosis repair using the H-repair at a single center. The proposed benefit of the procedure is its technical ease and simplicity (compared with Brom's 3-patch technique ${ }^{3}$ ) and the ability to easily maintain the longitudinal aortic dimension (which is presumed to be the main reason for right coronary artery distortion with the Doty repair). Three patients in the series required concomitant aortic arch augmentation. In a median follow-up time of 2.6 years, although there were no coronary issues or deaths, 1 patient developed severe aortic valve insufficiency, which may be attributed to the valve morphology and previous intervention.

The technique may be effective for patients who have localized disease morphology with an adequate-sized left coronary sinus that does not require augmentation. Another potential beneficiary of this technique may be a patient who needs concomitant aortic arch repair by extending the anterior patch onto the distal aorta. As has been described previously, ${ }^{2,4}$ patients with diffuse rather than the localized type of supravalvular stenosis are more likely to present with ascending aortic and arch involvement and would not be optimal candidates for this proposed modification; they would be better served with Brom's 3-patch repair. Although this technique may have some advantages over the Doty technique, longer follow-up will be needed to

From the Department of Cardiovascular Surgery, Children's National Hospital, Washington, DC.

Disclosures: The author reported no conflicts of interest.

The Journal policy requires editors and reviewers to disclose conflicts of interest and to decline handling or reviewing manuscripts for which they may have a conflict of interest. The editors and reviewers of this article have no conflicts of interest.

Received for publication Jan 9, 2021; revisions received Jan 9, 2021; accepted for publication Jan 13, 2021; available ahead of print Jan 19, 2021.

Address for reprints: Pranava Sinha, MD, Department of Cardiovascular Surgery, Children's National Hospital, 111 Michigan Ave, NW, Washington, DC 20010 (E-mail: psinha@childrensnational.org).

JTCVS Techniques 2021;6:120

2666-2507

Copyright $@ 2021$ The Authors. Published by Elsevier Inc. on behalf of The American Association for Thoracic Surgery. This is an open access article under the CC BY-NCND license (http://creativecommons.org/licenses/by-nc-nd/4.0/).

https://doi.org/10.1016/j.xjtc.2021.01.014

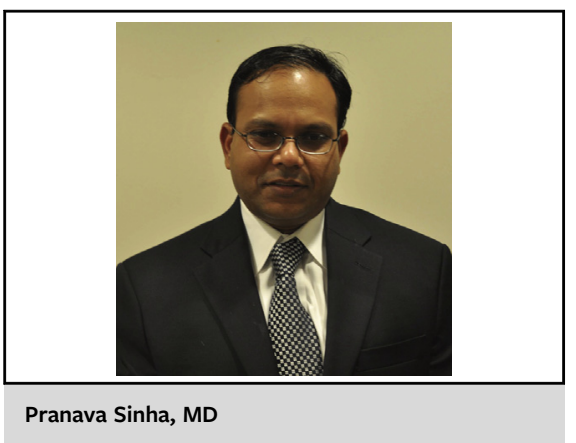

CENTRAL MESSAGE

This interesting technical modi-

fication for addressing supra-

valvular aortic stenosis may be an

alternative for a subset of pa-

tients with localized disease

sparing the left coronary sinus.

confirm these findings with regard to need for reintervention in the longer term.

The primary question is not whether or not the H-repair is superior to the Doty repair, but when should one choose to employ the H-repair instead, given the symmetric restoration of the aortic root anatomy ${ }^{5}$ and excellent early and late outcomes achieved with the multisinus Brom's 3patch repair technique $?^{6,7}$ As experience and longer-term outcomes are better defined, perhaps in a selected group of patients with localized pathology the simpler H-repair may be the procedure of choice.

\section{References}

1. Luo S, Haller C, Deng MX, Honjo O. H-repair in supravalvular aortic stenosis. J Thorac Cardiovasc Surg Tech. 2021;6:114-7.

2. Doty DB, Polansky DB, Jenson CB. Supravalvular aortic stenosis. Repair by extended aortoplasty. J Thorac Cardiovasc Surg. 1977;74:362371.

3. Brom AG. Obstruction of the left ventricular outflow tract. In: Cardiac Surgery: Safeguards and Pitfalls in Operative Technique. Philadelphia, PA: LippincottRaven; 1988:276-80.

4. Peterson TA, Todd DB, Edwards JE. Supravalvular aortic stenosis. J Thorac Cardiovasc Surg. 1965;50:734-41.

5. Hazekamp MG, Kappetein AP, School PH, Ottenkamp J, Witsenburg M, Huysmans HA, et al. Brom's three-patch technique for repair of supravalvular aortic stenosis. J Thorac Cardiovasc Surg. 1999;118:252-8.

6. Fricke TA, D'Udekem Y, Brizard CP, Wheaton G, Weintraub RG, Konstantinov IE. Surgical repair of supravalvular aortic stenosis in children with williams syndrome: a 30-year experience. Ann Thorac Surg. 2015;99: $1335-41$.

7. Kaushal S, Backer CL, Patel S, Gossett JG, Mavroudis C. Midterm outcomes in supravalvular aortic stenosis demonstrate the superiority of multisinus aortoplasty. Ann Thorac Surg. 2010;89:1371-7. 